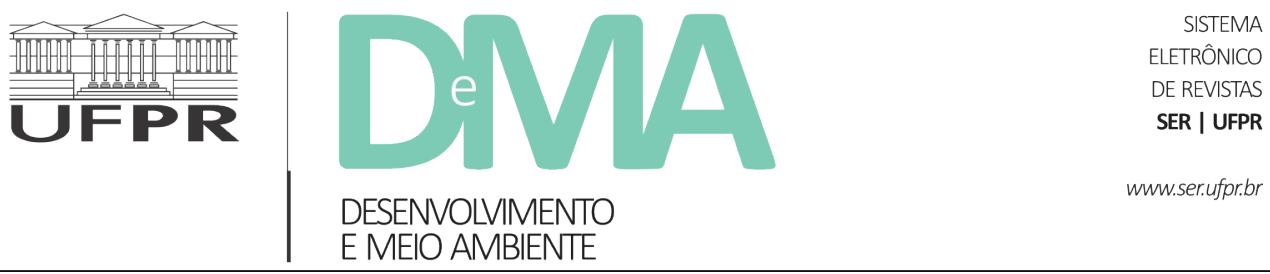

\title{
Editorial
}

\section{Anos do Legado de Chico Mendes}

\section{Years of the Legacy of Chico Mendes}

A edição especial da revista Desenvolvimento e Meio Ambiente sobre 30 Anos do Legado de Chico Mendes reúne autores de universidades, instituições de pesquisa, organizações da sociedade civil, órgãos públicos e pensadores independentes, nacionais e internacionais, para homenagear o legado do líder seringueiro e ambientalista. Com essa publicação, a revista Desenvolvimento e Meio Ambiente (DMA) do Programa de Pós-Graduação em Meio Ambiente e Desenvolvimento (PPGMADE), da Universidade Federal do Paraná (UFPR), se destaca no debate socioambiental do país ao sistematizar e refletir sobre três décadas de história de uma das mais inovadoras iniciativas de conciliação entre desenvolvimento e meio ambiente, as Reservas Extrativistas (Resex).

\section{Contexto}

Nascido em Xapuri, no estado do Acre, Francisco (Chico) Mendes Filho, representa a história dos migrantes nordestinos que foram para a Amazônia durante os diferentes ciclos de expansão da economia da borracha, entre 1880 e 1945 . Ativida- de desenvolvida em áreas isoladas e distantes do mercado, onde estavam localizadas as seringueiras nativas, a organização da produção da borracha na Amazônia foi caracterizada por um sistema de troca de mercadorias de consumo pelo produto extrativo, a preços desiguais, o sistema de aviamento, que tornava os seringueiros permanentemente endividados e "presos" aos "patrões", como eram denominados os seringalistas, proprietários ou administradores dos seringais.

Desde a metade da década de 1960, quando foi suspensa a política de subsídio ao preço da borracha, que era mantida desde o final da Segunda Guerra Mundial, seringalistas abandonaram a exploração dos seringais, impossibilitados de manter funcionando o sistema de aviamento. Seringueiros, castanheiros e outros extrativistas, em grande parte da Amazônia, passaram a viver dos recursos da floresta, comercializando seus produtos por conta própria e produzindo para a própria subsistência, caracterizando-se como posseiros em um modo de vida autônomo típico de um campesinato florestal (Barbosa de Almeida, 1993). 
Ao suspender os subsídios para a borracha, o governo militar sinalizou sua política para a Amazônia, baseada no mito do território vazio, negando a existência de populações indígenas e tradicionais que habitavam milenar e secularmente a região. A ideologia vigente era a de que a Amazônia precisava ser ocupada por razões de segurança nacional. Com incentivos fiscais a região foi aberta a grandes empresas agropecuárias do centro-sul do Brasil e, patrocinados pelo Estado, foram criados centenas de projetos de colonização para pequenos produtores de diferentes regiões do país, dividindo e retalhando o tecido florestal em pequenos lotes.

A derrubada e queima da floresta para implantação de projetos agropecuários de larga escala, foi acompanhada da expulsão dos seringueiros de suas posses e representou a perda do meios de vida de centenas de famílias. Sem escolaridade nem outra profissão, e com longa tradição de vida e de identidade com a floresta, os seringueiros, em Xapuri, se uniram para defender seus direitos de posse, assegurados pelo Estatuto da Terra, com o apoio da Confederação Nacional dos Trabalhadores na Agricultura (Contag). Inventaram um meio genuíno e pacífico de reagir, os chamados empates às derrubadas, caracterizados pela organização de um mutirão de homens e mulheres que se dirigiam à posse de um seringueiro onde ocorria o desmatamento, interrompiam a atividade, indo em seguido ao órgão ambiental e ao Sindicato dos Trabalhadores Rurais negociar uma solução. Ao longo dos anos 1980, em vários seringais, os seringueiros de Xapuri conseguiram interromper o desmatamento e continuar vivendo na floresta.

$\mathrm{O}$ que diferenciou este, de outros movimentos surgidos por razões semelhantes, na mesma época, em diferentes partes da Amazônia, foi o fato de ter se transformado, de uma estratégia defensiva, em uma organização propositiva -- de re-existência. O custo foi alto para muitos líderes desse movimento, sendo Wilson Pinheiro, que inventou os empates e Chico Mendes, que os transformou em uma estratégia de luta, os mais conhecidos.

Com o início da democratização do país, o movimento nascido em Xapuri se uniu a outros, semelhantes, em diferentes partes da Amazônia. Liderando um processo de articulação nacional e internacional, buscando parceiros na academia e nas organizações não governamentais, a ideia de Chico Mendes e de seus aliados começou a tomar forma durante $1^{\circ}$ Encontro Nacional dos Seringueiros, realizado em outubro de 1985 em Brasília, com as seguintes características: a não divisão da floresta em lotes, a não regularização da posse como propriedade privada, os territórios tradicionalmente ocupados incorporados ao domínio da União e cedidos ao uso para seringueiros, castanheiros e outros grupos sociais semelhantes. A essa ideia deram o nome de Reserva Extrativista, inspirando-se nas Reservas Indígenas e, para lutar pela implantação da proposta, criaram o Conselho Nacional dos Seringueiros $-\mathrm{CNS}$.

\section{Os legados de Chico Mendes}

Patrimônio socioambiental: territórios de uso comum de comunidades extrativistas tradicionais.

Como resultado das pressões do movimento seringueiro e, no contexto da repercussão internacional do assassinato de Chico Mendes, suas propostas foram incorporadas pelo Estado brasileiro e 
transformadas em políticas públicas. Em 1987, no âmbito da reforma agrária, foi criada a modalidade Projeto de Assentamento Extrativista (PAE). Em 1990, por decreto presidencial, a Reserva Extrativista foi formalizada como unidade de conservação, na expressão plena do conceito formulado uma década antes. Ao mesmo tempo foram criadas as primeiras quatro Resex, entre elas a Resex Chico Mendes, abarcando todos os seringais onde aconteceram os empates ao desmatamento.

O inovador nessa história é o fato de grupos sociais pobres, sem importância econômica nem poder político, isolados da sociedade brasileira e do mundo, terem formulado uma solução para a destruição da floresta e os conflitos a ela associados e transformado essa alternativa em uma política pública que beneficia, ao mesmo tempo, milhares de famílias e milhões de hectares da floresta tropical mais extensa do planeta (Allegretti, 2002). Ter um legado que subsiste às mudanças aceleradas deste século, e à cultura de destruição socioambiental que rege as políticas de modernização do país, merece uma reflexão e um reconhecimento.

Em 2000 as Reservas Extrativistas foram integradas ao Sistema Nacional de Unidades de Conservação (SNUC), que também criou a modalidade Reserva de Desenvolvimento Sustentável (RDS) agrupando-as como Unidades de Conservação de Uso Sustentável. Nos anos seguintes, outras modalidades semelhantes ao PAE foram criadas, o Projeto de Desenvolvimento Sustentável (PDS) e o Projeto de Assentamento Florestal (PAF).

O conceito de "seringueiro" também se ampliou para incluir outras modalidades de uso dos recursos naturais, classificadas de extrativistas, dando uma conotação contemporânea ao conceito "extrativismo", antes visto como uma etapa "atra- sada" da humanidade tendente ao desaparecimento. A conotação do termo, atualizada no tempo, circunscreve-se ao extrativismo vegetal, que inclui atividades de coleta e de transformação de produtos da biodiversidade, em muitos casos associados à diversificação produtiva com a inclusão de atividades agrícolas complementares, para subsistência e comercialização, o denominado agroextrativismo. $\mathrm{O}$ qualificativo que todas essas diferentes modalidades de uso e exploração de baixo impacto dos recursos naturais têm em comum é sua tradicionalidade.

Todos esses atributos são hoje sintetizados na expressão "comunidades extrativistas tradicionais" que se caracterizam pela gestão e uso coletivo de territórios formalmente destinados, por meio de concessão de direito real de uso, pelo Estado brasileira. No mesmo sentido, a entidade representativa dos beneficiários das Reservas Extrativistas, passou a se chamar Conselho Nacional das Populações Extrativistas, com a mesma sigla, CNS.

Trinta anos depois a realidade surpreende. As Reservas Extrativistas federais e estaduais, em todo o Brasil, totalizam 94 unidades, abrangendo 15,5 milhões de hectares. A maior parte delas está na Amazônia, um total de 79 unidades, com 15 milhões de hectares. Surpreendente, também, é o número de RDS criadas pelos estados amazônicos, um total de 20 unidades, abrangendo 8,5 milhões de hectares; agregando duas RDS federais e 10 criadas em outras regiões do país, chega-se a 32 unidades e 8,6 milhões de hectares. No total, são 126 unidades e 24 milhões de hectares (4,6\% da Amazônia) provendo serviços ambientais para o país e o planeta.

Em 1992 houve ampliação do conceito de Reserva Extrativista para a realidade da costa brasileira, com a criação da primeira Reserva Extrativista Marinha, em Santa Catarina. Essa transposição da 
proposta original, baseada na realidade florestal, muitas vezes ocorreu sem se ater às especificidades da cultura e dos ambientes marinhos. De lá para cá, todavia, as Resex marinhas se expandiram pela zona costeira de todo o país e os dois grupos se consolidaram, mesmo considerando os desafios que cada modalidade ainda enfrenta na atualidade. Do total mencionado de Resex, 28 são marinhas.

Com base no exposto, pode-se afirmar que a instituição das Reservas Extrativistas e as iniciativas delas derivadas, constituem o legado principal de Chico Mendes, sendo defendido, ampliado e consolidado por mais de 600 mil pessoas e por centenas de associações e cooperativas, grandes e pequenas, que têm a responsabilidade de gerenciar, juntamente com os órgãos governamentais, esse patrimônio: o Instituto Chico Mendes de Conservação da Biodiversidade (ICMBio) em nível federal, as secretarias de meio ambiente em nível estadual e o Incra para os assentamentos.

A unidade desse movimento criado pelos seringueiros da Amazônia em 1985, sob a liderança de Chico Mendes e de seus sucessores, vem sendo mantida, desde então, pelo Conselho Nacional das Populações Extrativistas. As Reservas Extrativistas marinhas também têm uma entidade representativa em nível nacional, a Comissão Nacional para o Fortalecimento das Reservas Extrativistas e dos Povos Extrativistas Costeiro Marinhos - CONFREM, representando 18 estados brasileiros.

Dessa forma, o movimento seringueiro, criado na década de 1970 no Acre, e ampliado para toda a Amazônia a partir de 1990, interrompeu a dinâmica de expansão predatória da fronteira econômica na região e de seus impactos sociais e ambientais, e a reverteu em um amplo mosaico de territórios de uso sustentável dos recursos naturais, na fímbria da floresta com o desmatamento, protegendo-a.

\section{Novos paradigmas e campos de} conhecimento

Uma conjugação de fatores e acontecimentos gerou a sinergia entre as questões ambientais sociais no início da década de 1990 -- inspirada no movimento dos seringueiros --- e deu origem ao termo socioambiental, hoje consolidado como uma nova abordagem de conservação e desenvolvimento (Becker, 1990).

Um sinal de que algo novo estava surgindo no cenário internacional, com repercussões para a Amazônia, aconteceu imediatamente após o $1^{\circ} \mathrm{En}$ contro Nacional dos Seringueiros, em novembro de 1985, quando o CNS foi convidado a participar, juntamente com a União das Nações Indígenas (UNI) de uma reunião com Gro Brundtland, coordenadora do relatório Nosso Futuro Comum (Brundtland, 1987), base para as mudanças assumidas pelos países durante a Conferência da ONU sobre Meio Ambiente e Desenvolvimento, em 1992, quando foi legitimado e codificado o enfoque em comunidades locais e os benefícios sociais das florestas, em documentos como a Agenda 21. Também dessa conferência emergiu o abrangente Programa Piloto para a Proteção das Florestas Tropicais Brasileiras (PPG-7), o qual apoiou e difundiu experimentos de desenvolvimento baseado na floresta.

Desde então, pesquisadores e jornalistas passaram a visitar Chico Mendes em Xapuri para conhecer o modo de vida e o movimento contra os desmatamentos. De 1987 a 1988, o documentarista britânico Adrian Cowell registrou a trajetória de Chico e seus filmes foram amplamente divulgados nos Estados Unidos e Europa, como parte de uma campanha internacional de proteção às florestas tropicais. 
O que o mundo desenvolvido estava buscando era um elo entre a defesa do meio ambiente e a eliminação da pobreza. O movimento seringueiro e indígena, organizado na Aliança dos Povos da Floresta, não somente estabelecia esse elo como rompia com a ideia de que a pobreza era responsável pela degradação ambiental, conceito propagado a partir da Conferência da ONU sobre o Ambiente Humano em 1972, em Estocolmo. Ainda mais, o protagonismo de grupos sociais pobres na apresentação de soluções para proteger as florestas e, ao mesmo tempo, as pessoas, questionava o pressuposto do conservacionismo mundial que pregava a criação de parques nacionais intocados nos quais não caberia a presença humana. O conceito de "reservas de uso sustentável," habitadas por comunidades tradicionais, passou a fazer parte do léxico dos regimes de unidades de conservação em muitos países.

No Acre, o "Governo da Floresta", em 1998, foi favorecido por este impulso político mais amplo (Schmink et al., 2014), e contribuiu para articular uma visão integrada do desenvolvimento com base florestal, visando promover a "florestania" - cidadania com uma identidade florestal -- como uma bandeira regional expressiva na fronteira socioambiental da Amazônia (Becker, 1990, p. 158). O experimento no Acre com investimentos de longo prazo em um desenvolvimento baseado na floresta foi implementado em sincronia com políticas nacionais e internacionais durante duas décadas.

Mais recentemente, o reconhecimento da importância das florestas e dos serviços ambientais prestados pelas áreas habitadas por comunidades florestais na Amazônia, no equilíbrio climático global, tornou-as protagonistas, juntamente com os povos indígenas, no esforço brasileiro e mundial de impedir as consequências das mudanças climáticas globais. Os serviços ambientais prestados por essas populações ao Planeta já são reconhecidos, bem como o papel que podem desempenhar na manutenção do equilíbrio climático, não somente pela extensão e importância das áreas em que vivem, mas também pelo conhecimento que adquiriram na observação da natureza.

Pelos fatos relatados pode-se reconhecer a resiliência do conceito formulado pelos seringueiros em 1985, tornado mundialmente conhecido pela voz de Chico Mendes. Com pequenas diferenças, a essência permanece a mesma - territórios públicos contínuos cedidos ao uso sustentável para comunidades tradicionais, visando valorizar as florestas e seu uso.

$\mathrm{O}$ alcance do ideário de Chico Mendes, e do seu legado, não permitem, todavia, o entendimento de que as Reservas Extrativistas constituem panaceia para todos os problemas sociais e dos ecossistemas florestais e costeiros brasileiros; há que se ter em conta a existência de vários entraves e conflitos socioambientais no interior das Resex, e em seus entornos, a serem equacionados por políticas mais amplas, de caráter macro-socioambiental, assim como pela introdução de inovações na gestão sustentável dos recursos e dos territórios, inspiradas no ideário de Chico Mendes.

A Edição Especial 30 Anos do Legado de Chico Mendes é formada por 23 artigos organizados em quatro grandes temas: Evolução das Políticas, Reservas Florestais, Reservas Marinhas, Valorização dos Recursos Naturais. Mesmo sem contemplar toda a relevante produção sobre o tema, os artigos inscritos nesta edição especial, ancorados em pesquisas originais, em universidades, organizações não governamentais, órgãos de governo, e em vivências com a história de Chico Mendes, contribuem 
significativamente, sob distintos ângulos, com o debate dos desafios socioambientais, presentes e futuros, para a viabilização das Reservas Extrativistas, ampliando a qualidade de vida das populações tradicionais que nelas vivem.

\author{
Mary Allegretti \\ Lucia Helena de Oliveira Cunha \\ Marianne Schmink \\ Organizadoras
}

\title{
Referências
}

Allegretti, M. H. A Construção Social de Políticas Ambientais. Chico Mendes e o Movimento dos Seringueiros. Tese de Doutorado apresentada ao Centro de Desenvolvimento Sustentável da Universidade de Brasília, 2002.

Barbosa de Almeida, M. W. Rubber Tappers of the Upper Jurua River, Brazil: The Making of a Forest Peasantry. Cambridge, Tese (Ph.D. em Antropologia Social) - University of Cambridge, 1993.

Becker, B. Amazônia. São Paulo: Ática, 1990.

Brundtland, G. H. Nosso Futuro Comum. Rio de Janeiro: Fundação Getúlio Vargas, 1987.

Cunha, L. H. O. Reservas Extrativistas: uma alternativa de produção da biodiversidade. São Paulo. NUPAUB/ USP, 2001.

Schmink, M.; Duchelle, A.; Hoelle, J.; Leite, F.; d'Oliveira, M. V.; Vadjunec, J.; Valentim, J.; Wallace, R. Forest citizenship in Acre, Brazil. In: Katila, P.; Galloway, G.; de Jong, W.; Pacheco, P.; Mery, G. (Eds.). Forests Under Pressure - Local Responses to Global Issues. Vienna: International Union of Forest Research Organizations (IUFRO), World Series, Volume 32, 2014, p. 31-47. 